\title{
A Threshold Distribution Hypothesis for Packet Storage of Insulin and Its Mathematical Modeling
}

\author{
Gerold M. GrodsKY \\ From the Metabolic Research Unit and Department of Biochemistry and \\ Biophysics, University of California, San Francisco, California 94122
}

A BSTRACT Phases of insulin release were studied in the perfused pancreas during a variety of glucose stimulation patterns. Patterns included staircase stimulations, constant prolonged single steps, restimulations, and ramp functions. Except at low concentrations, prolonged single steps of glucose elicited early spikes of insulin and a slowly rising second phase. Total insulin in the initial spikes increased with higher glucose concentrations. However, the time-related pattern of these spikes was similar in all cases; ratios of initial secretion rate to total insulin released were constant. Total insulin released in this early phase approximated a sigmoidal function of glucose concentration; mathematical differentiation of this function gave a skewed bell-shaped distribution curve. Staircase stimulations caused insulin to be released as a series of transient spikes which did not correlate with the increment of glucose but rather to the available insulin for a given glucose concentration minus that released in previous steps. The sum of total insulin released as spikes in a staircase series leading to a given glucose concentration was the same as when that concentration was used as a single step. Interrupted prolonged glucose infusions indicated the second phase of insulin release could prime the pancreas and that the first and second phases were interrelated. When glucose was perfused as ramp functions of slow, increasing, concentration, phasic response disappeared.

A previous two-compartmental model was expanded to include a threshold or sensitivity distribution hypothesis. This hypothesis proposes that labile insulin is not stored in a homogeneous form but as packets with a bell-shaped distribution of thresholds to glucose. These packets respond quickly when their threshold levels to

This work was presented in part at the Pan American Congress of Endocrinology, Sao Paulo, 1970; and the International Diabetes Association, Buenos Aires, 1970.

Received for publication 24 January 1972 and in revised form 9 March 1972. glucose are reached or exceeded. Data from single step stimulations were utilized for constructing a mathematical model which simulated satisfactorily the various stimulation patterns.

\section{INTRODUCTION}

Studies performed in vitro (1-3) and in vivo (4-6) have established that the pancreas responds to constant stimulation with a multiphasic pattern of insulin release.

On the basis of these patterns we initially described a two-compartmental mathematical model which suggested that a small amount of stored insulin may be in a form particularly labile to stimulating agents (7-9). Subsequent studies, using continuous staircase stimulations, showed that the characteristic initial spike of insulin release was not due to depletion of a single labile compartment since more insulin was elicited at each higher glucose step $(10,11)$.

In the present study, a working hypothesis is described which suggests that insulin in the labile form or "compartment" is nonhomogeneous ${ }^{1}$ consisting of elemental packets of insulin distributed in a bell-shaped function as to their glucose thresholds. These packets rapidly release insulin when their thresholds to glucose are reached or exceeded. The hypothesis permits simulation of the observed insulin secretion after a variety of glucose stimulation patterns including single step, staircase, and ramp functions.

Since similar spike patterns of release have been observed for other endocrine systems $(12,13)$, the threshold distribution hypothesis may apply to systems other than the $\beta$-cell.

\footnotetext{
1 By definition, a compartment is usually considered homogeneous. Though our labile stored form of insulin is now presumed to be nonhomogeneous, the term compartment is sometimes retained for consistency with previous discussions (7-9).
} 


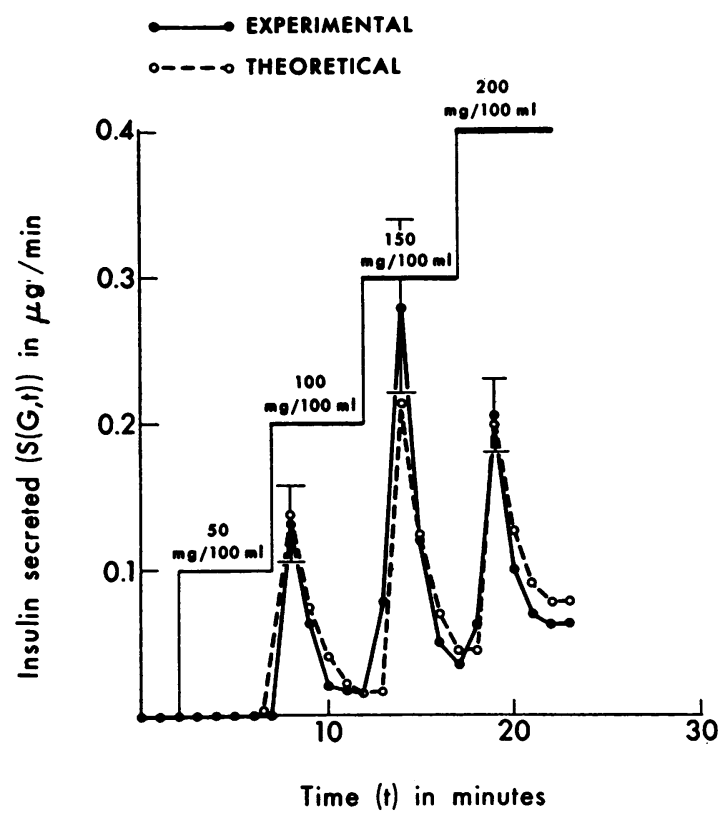

FIGURE 1 Insulin secretion during staircase stimulations with $50 \mathrm{mg} / 100 \mathrm{ml}$ increments of glucose. Values in $\mathrm{mg} / 100 \mathrm{ml}$ refer to glucose concentration at each $5 \mathrm{~min}$ step. Solid line shows experimental results; $\$$ is mean \pm SE., $n=7$. Broken line shows results of computer simulation (equation 12 and 13) based on the model in Fig. 6 and the data from Fig. 2.

\section{METHODS}

Specific details for the in vitro perfusion technique of the rat pancreas and the immunoassay for rat insulin have been described in our earlier publications $(1,2)$. In brief, the pancreas with the adjacent stomach, spleen, and part of the duodenum was removed from fasted rats whose blood sugars averaged $80 \mathrm{mg} / 100 \mathrm{ml}$. The preparation was placed onto the perfusion apparatus and perfusion media, consisting of $4 \%$ albumin (Cutter Laboratories, Berkeley, Calif. and Abbott Laboratories, Pasadena, Calif. ${ }^{2}$ ) and phosphate-bicarbonate buffer, was introduced into the celiac artery. The complete effluent was collected from the portal vein every 30 or $60 \mathrm{sec}$ after a single passage through the pancreas. Flow rates were 10 $\mathrm{ml} / \mathrm{min}$.

After a 13 min equilibration period, glucose was introduced by multiple infusion pumps in a variety of patterns, including prolonged single-step functions, interrupted steps, and staircase functions. Ramp functions of linearly increasing concentrations, but varying in slope, were achieved by means of an LKB gradient mixer introduced before the perfusion pump.

All simulations were done on a digital computer PDP-12 using 8K-FOCAL (1969) language.

\section{RESULTS}

Though the results of staircase glucose stimulations (Fig. 1) prompted development of the packet hypothe-

${ }^{2}$ We wish to express our gratitude to Doctors M. Mozen and A. Pappenhangen of Cutter Laboratories, Berkeley, Calif. and Dr. J. Holper of Abbott Laboratories, South Pasadena, Calif. for their generous assistance in providing the large supplies of albumin necessary for these studies. sis, the single step glucose stimulations (Fig. 2) provided all data for formulation of the mathematical model. It is emphasized that once established by the data in Fig. 2, all simulations were made without modification of the model and independently of the respective experimental results. The simulations were plotted together with the experimental data to reduce the number of figures.

Fig. 1 shows the summary of staircase glucose stimulations. Glucose at $50 \mathrm{mg} / 100 \mathrm{ml}$ had no detectable effect on release of insulin. When glucose concentration was raised to $100 \mathrm{mg} / 100 \mathrm{ml}$, the characteristic spike response occurred. Despite maintained glucose levels, secretion rates fell logarithmically to less than

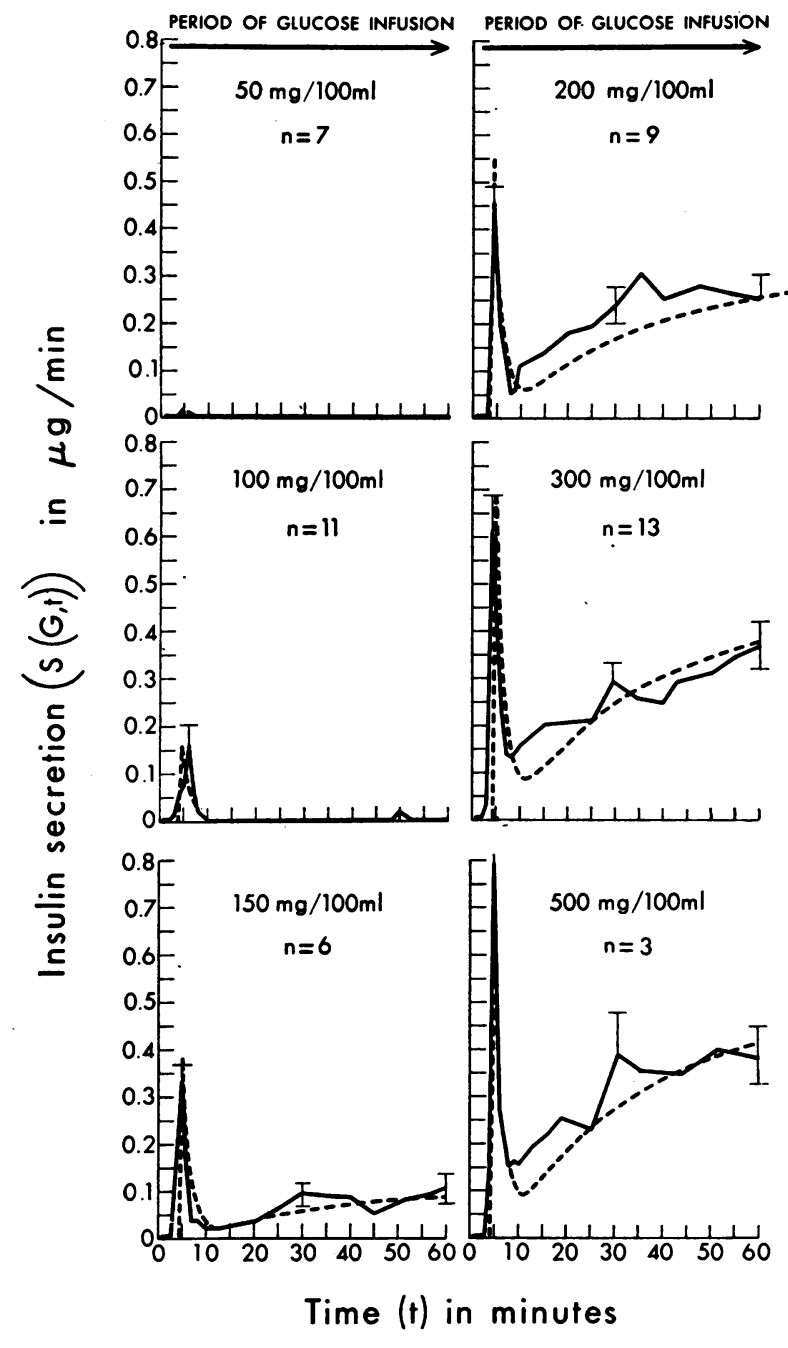

FIGURE 2 Insulin secretion during single-step continuous perfusion with glucose. Solid lines show experimental results; $\$$ is mean \pm SE. Broken line shows results of computer simulations (equations 12 and 13). 


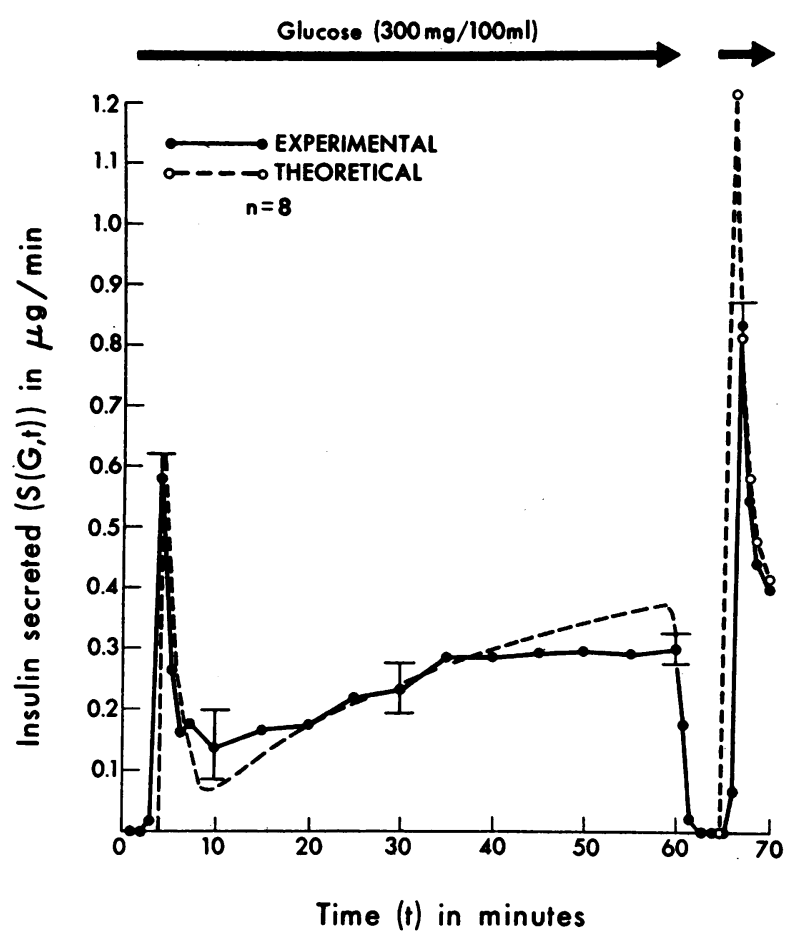

FIGURE 3 Insulin secretion during single-step perfusion with glucose $(300 \mathrm{mg} / 100 \mathrm{ml})$. Stimulation was interrupted during a rest period from minutes 60 through 65 . Solid line shows experimental results; ${ }_{\uparrow}^{\top}$ is mean $\pm S E$. Broken line shows results of computer simulation (equations 12 and 13).

$15 \%$ of the peak rate during this period. However, the pancreas still responded sharply to a third increment of glucose $(150 \mathrm{mg} / 100 \mathrm{ml})$ with another and larger response. Again, the pancreas was unresponsive or refractory during the second half of this perfusion. When glucose concentrations were suddenly increased to $200 \mathrm{mg} / 100 \mathrm{ml}$, only a smaller spike occurred. Total insulin secreted during the spikes at 100,150 , and 200 $\mathrm{mg}$ glucose $/ 100 \mathrm{ml}$ were $0.22 \pm 0.03 \mu \mathrm{g}(1 \times \mathrm{SE}), 0.46$ $\pm 0.06 \mu \mathrm{g}$, and $0.24 \pm 0.04 \mu \mathrm{g}$, respectively. ${ }^{3}$ The response at $200 \mathrm{mg} / 100 \mathrm{ml}$ was significantly less than that at $150 \mathrm{mg} / 100 \mathrm{ml}(P<0.01)$. The minimal secretion rate during each stimulation progressively increased, partially because total release was not quite completed within 5 min and partially as a reflection of a slowly increasing secondary phase.

Fig. 2 shows the results obtained when glucose, as a continuous single step, was perfused through the pancreas at different concentrations for $1 \mathrm{hr}$. Insulin secretion was not detectable (less than $0.001 \mu \mathrm{g} / \mathrm{ml}$ or $0.01 \mu \mathrm{g} / \mathrm{min}$ ) when glucose concentrations were maintained at $50 \mathrm{mg} / 100 \mathrm{ml}$. At $100 \mathrm{mg} / 100 \mathrm{ml}$, insulin

${ }^{8}$ Total insulin secreted was calculated as the sum of the areas under each peak minus the corresponding, gradually increasing baseline secretion. release was prompt, but within minutes secretion was undetectable throughout the subsequent continuous perfusion (less than or equal to $0.01 \mu \mathrm{g} / \mathrm{min}$ ). At 150 $\mathrm{mg} / 100 \mathrm{ml}$ glucose, the characteristic multiphasic response was obtained $(2,8)$. With increasing glucose concentration, insulin secretion increased both in the first and second phases, reaching a maximum in each phase as glucose concentration approached $500 \mathrm{mg} / 100$ $\mathrm{ml}$. At all glucose concentrations the rapid rise and fall of the first phase occurred within 3-4 min after initiation of the stimulation. The second phase required somewhat higher glucose concentrations to be detectable, but at all concentrations it was characterized by a progressive increase in the rate of insulin secretion which approached constant levels by $60 \mathrm{~min}$.

The sum of insulin secreted in the spikes during the staircase stimulations up to $200 \mathrm{mg} / 100 \mathrm{ml}$ in Fig. 1 averaged $0.92 \pm 0.11 \mu \mathrm{g}$ (see above). That secreted in the spike caused by $200 \mathrm{mg} / 100 \mathrm{ml}$ glucose presented as a single step function (Fig. 2) was $1.08 \pm 0.08 \mu \mathrm{g}$. The amounts of insulin secreted in both cases was not statistically different.

Fig. 3 shows the results when glucose at high concentration was perfused for $1 \mathrm{hr}$; after a subsequent

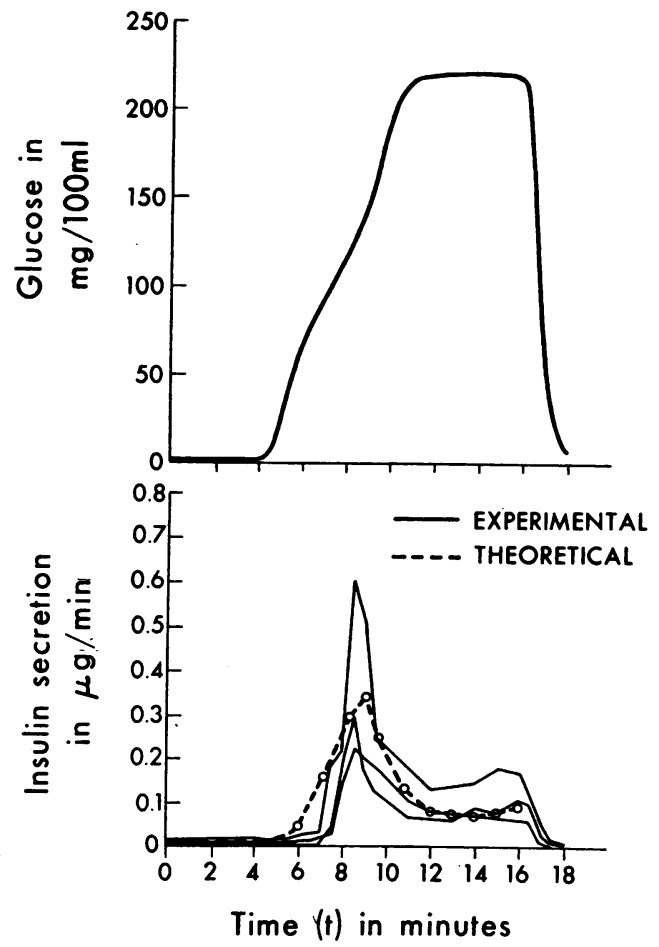

FIgURE 4 Insulin secretion during glucose administration as a fast ramp function (about $50 \mathrm{mg} / 100 \mathrm{ml}$ increment $/ \mathrm{min}$ ). Upper curve shows glucose levels. Solid line in lower curve shows experimental results (data from reference 1). Broken line in lower curve shows computer simulation (equation 20 and formula 21). 

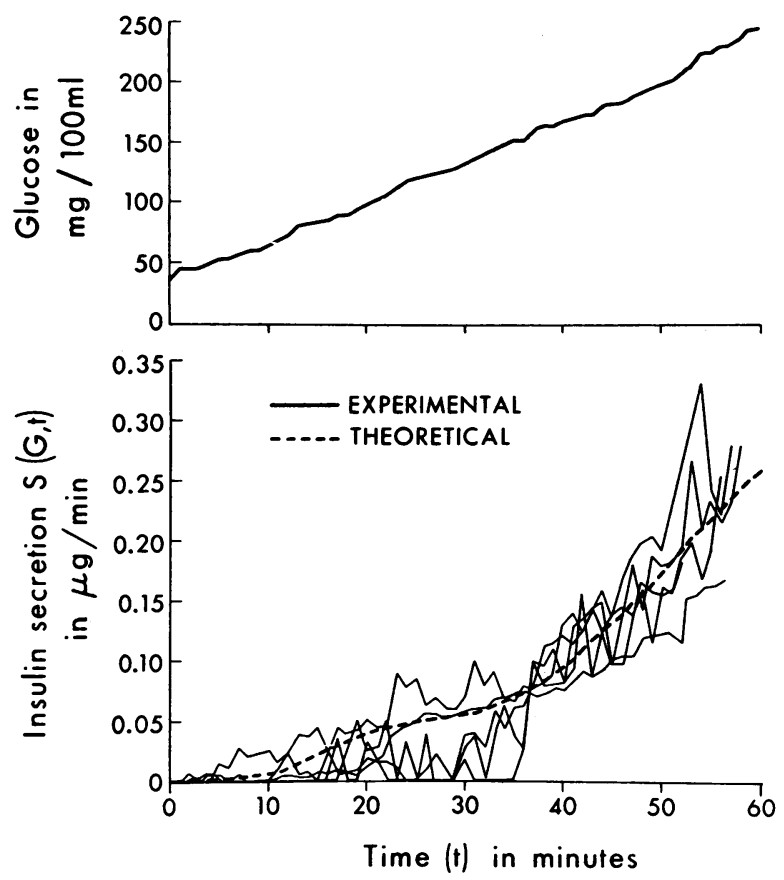

FIgURE 5 Insulin secretion during glucose administration as a slow ramp function (about $5 \mathrm{mg} / 100 \mathrm{ml}$ increment $/ \mathrm{min}$ ). Upper curve shows glucose levels. Solid line in lower curve shows experimental results. Broken line in lower curve shows computer simulation (equation 20 and formula 21).

5 min rest, the pancreas was exposed to a second stimulation with the same glucose concentration. As we previously noted (7-9), prolonged high glucose stimulation results in a pancreas hypersensitive to further stimulation. In these representative experiments, maximum secretion rate during the second glucose stimulation was significantly greater than that when glucose was first administered $(P<0.01)$.

Figs. 4 and 5 give the experimental results when glucose was presented to the pancreas in constantly increasing concentrations (ramp functions). Fig. 4 shows that the multiphasic response still occurred when glucose concentrations were increased to high levels during a $5 \mathrm{~min}$ period instead of as a rapid step. After a few minutes, a paradoxical decreasing secretion rate could be produced, despite ascending glucose levels.

When a period of $1 \mathrm{hr}$ was used to increase glucose from 50 to $250 \mathrm{mg} / 100 \mathrm{ml}$ (Fig. 5), insulin secretion gradually increased with little evidence of multiphasic responses.

\section{MODEL}

\section{General features}

The original two-compartmental model consisted of a large, and a small, labile compartment, the latter containing only a minute portion (ca. $2 \%$ ) of the total pancreatic insulin. Insulin could exchange between compartments though the rate was slow. Fig. 6 depicts the gross features of such a model, but includes also the refinement according to the present hypothesis: the labile form now consists of "packets" of insulin with similar capacity to release insulin in terms of time but whose threshold sensitivity to glucose varies according to a distribution density function. In the diagram, the distribution density function is schematically represented by the vertical density of circles. The amount of insulin acutely released by a given constant glucose concentration is related to the total amount of packets
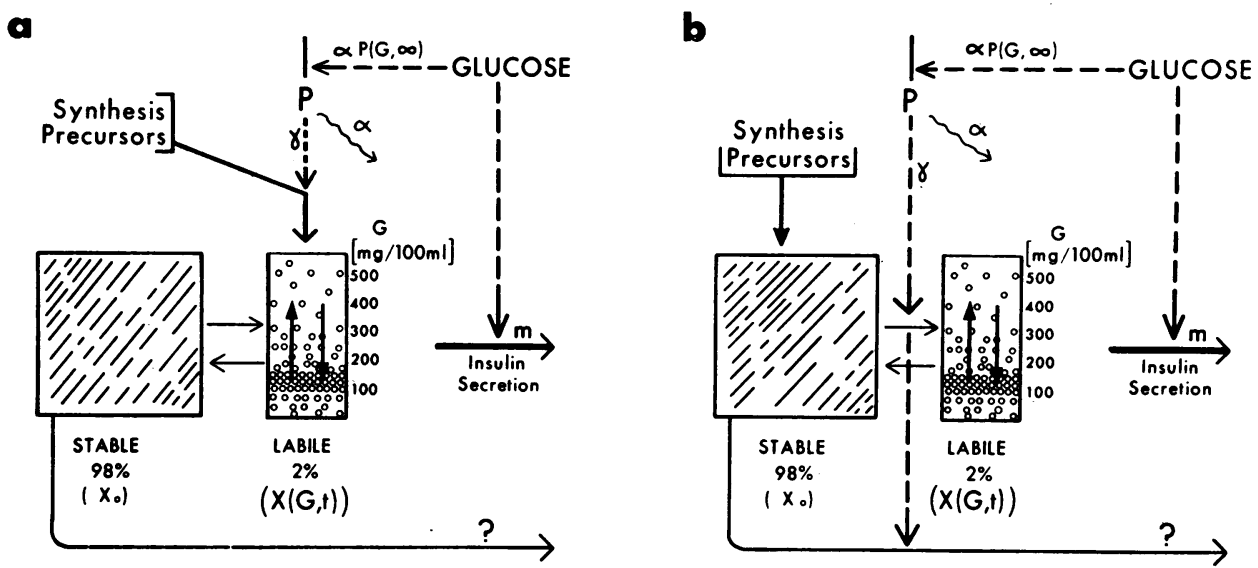

FIgURE 6 (a, b) Theoretical scheme for insulin secretion incorporating the hypothesis of a distribution of insulin packets which rapidly release insulin when their thresholds to glucose are reached or exceeded. Open circles in the small labile form represent distribution of the thresholdsensitive packets. Broken lines in the large stable form are for artistic balance; the distribution characteristics of this form are unknown. Figures $a$ and $b$ show the model if new insulin preferentially enters the small (Fig. 6a) or the large (Fig. 6b) storage forms. 


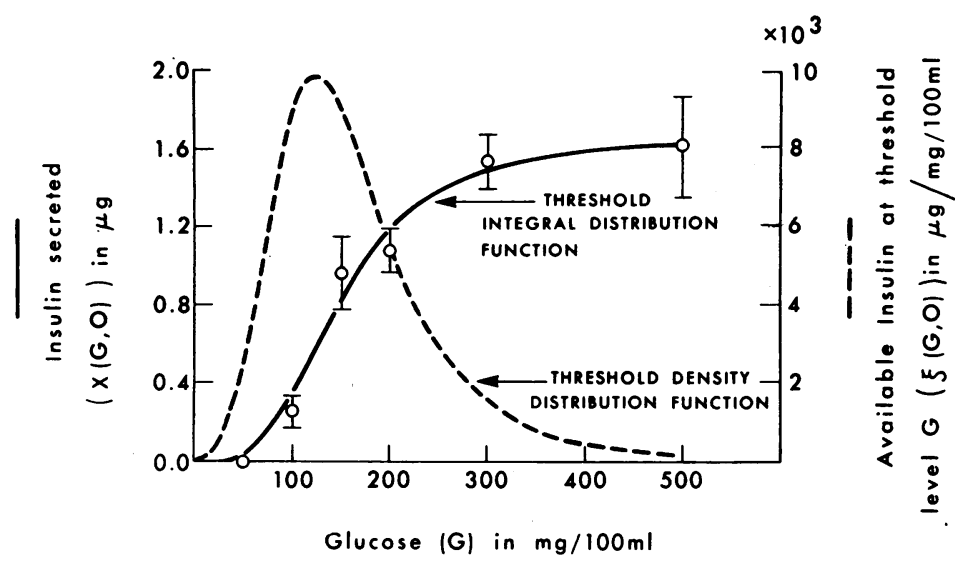

FIGURE 7 Total insulin secreted during the early phase (min 1-10). Data in open circles were taken from Fig. 2 ; is mean \pm SE. Solid line is a log-normal approximation to the experimental values (formula 2). Broken line is its mathematical derivative (formula 3 ).

(circles) whose thresholds are encompassed by the increment of glucose produced. After any change from the original steady state (either by partial emptying or refilling), the packets slowly re-equilibrate to their original distribution.

The model also takes into account an additional action of glucose to stimulate reappearance of new packets either via synthesis of insulin (de novo or by conversion from precursors) (Fig. 6a), or through activation of stable stored insulin (Fig. 6b). In the first case, a hypothetic provisionary or potentiation factor is assumed to mediate the new synthesis; in the second, the same factor controls the transport or activation of insulin from the more stable to the more labile form. As indicated in Fig. 6b, part of this labilized insulin may be released directly from the large compartment as well as by way of the labile storage form. The production of the provisionary factor is assumed to be dependent upon the instantaneous glucose concentration and in each scheme, its function is essentially the same: provision of insulin to the more labile storage state.

\section{Formulation}

Release of insulin from packets. For any glucose concentration there is a specific amount of releasable insulin, the amount in the packets whose sensitivity to glucose, expressed in the threshold level, $\theta$ (in units of glucose concentration), is between $\theta$ and $\theta+\mathrm{d} \theta$, i.e. $\xi(\theta, 0) \mathrm{d} \theta$. Here $\xi(\theta, 0)$ is the initial threshold distribution function. The total amount of insulin, releasable at a given glucose concentration $\mathrm{G}$, is then:

$$
X(G, 0)=\int_{0}^{G} \xi(\theta, 0) d \theta .
$$

The function $X(G, 0)$ is the initial integral distribution function which can be determined from the data in Fig. 2. This is plotted in Fig. 7 as the total amount of insulin released in the first phase (area under the initial spikes) against glucose concentration. Replotting these data on probability versus $\log \mathrm{G}$ grid, it was found that they satisfy a log-normal (skewed gaussian) density distribution function. For the purpose of simulation, this function is approximated analytically by:

$$
\mathrm{X}(\mathrm{G}, 0)=\frac{\mathrm{X}_{\mathrm{max}} \mathrm{G}^{k}}{C+\mathrm{G}^{k}}
$$

where $\mathrm{X}_{\max }$ is maximal releasable amount of labile insulin (1.65 $\mu \mathrm{g}$ of insulin per pancreas) and $C$ and $k$ are constant: $C=1.51 \times 10^{7}$ and $k=3.3$.

From this analytic expression, the (initial) density distribution function is determined by differentiating (2) with respect to $G$, viz:

$$
\xi(\theta, 0)=\mathrm{X}_{\max } \frac{k C \theta^{k-1}}{\left(C+\theta^{k}\right)^{2}} .
$$

Both (initial) distribution functions are shown in Fig. 7. The available insulin in the labile form for any step function or staircase function stimulation with glucose can be determined by inspection.

To compute the secretion rate, $S(G, t)$, for any time during the initial spike we assume a first order process, i.e., the appearance of insulin in the perfusate is proportional to the amount of available insulin in the packets, $\xi(\theta, \mathrm{t}) \mathrm{d} \theta$. Thus, at any constant glucose level, $\mathrm{G}$, and any time, $\mathrm{t}$ :

$$
\text { or } \quad \begin{aligned}
\dot{\xi}(\theta, \mathrm{t}) & =-\mathrm{m}(\mathrm{G}) \xi(\theta, \mathrm{t}), \\
\xi(\theta, \mathrm{t}) & =\xi(\theta, 0) \mathrm{e}^{-\mathrm{m}(G) \mathrm{t}},
\end{aligned}
$$


so that the secretion rate is:

$$
\begin{aligned}
& \mathrm{S}_{0}(\mathrm{G}, \mathrm{t})=\mathrm{m}(\mathrm{G}) \int_{0}^{\sigma .} \xi(\theta, \mathrm{t}) \mathrm{d} \theta \\
&=\mathrm{m}(\mathrm{G}) \mathrm{X}(\mathrm{G}, 0) \mathrm{e}^{-\mathrm{m}(G) \mathrm{t},}
\end{aligned}
$$

where $m(G)$ is the rate coefficient for release and $X(G, 0)$ is defined by equation 1 .

The observed function is not the instantaneous rate of insulin secretion as given by equation 6 , but its $1-\mathrm{min}$ in tegral,

$$
\begin{aligned}
S(G, t)=\int_{t}^{t+1} S_{0}(G, \tau) d \tau & \\
& =\left(1-e^{-m(G)}\right) X(G, 0) e^{-m(G) t} .
\end{aligned}
$$

Then,

$$
\mathrm{m}^{\prime}(\mathrm{G})=1-\mathrm{e}^{-\mathrm{m}(\mathrm{G})}=\frac{\mathrm{S}(\mathrm{G}, 0)}{X(G, 0)}
$$

$\mathrm{m}^{\prime}(\mathrm{G})$ may be determined from the ratio of the height to the area under the spike. As shown in Fig. 8 this ratio was approximately constant so we may conclude that the rate coefficient of insulin release is independent of glucose concentration, $\mathrm{m}(\mathrm{G})=\mathrm{m}=0.622 \mathrm{~min}^{-1}$.

Refilling of the labile storage form. At present, refilling involves at least three processes which are difficult to separate and quantitatively evaluate. These include: (a) reversible exchange from the large compartment, (b) a potentiating effect of glucose to increase provision of additional insulin to the labile packet system; and, (c) redistribution of packets within the labile system to approach the original distribution.

On the basis of previous studies (9), the first process was used in current simulations but employed small values for the exchange coefficients $(0.001$ and 0.01 $\mathrm{min}^{-1}$ ). This process is not included in the following mathematical treatment in order to more clearly present newer aspects of the model.

Because of the slow increase in the second phase of insulin release and its gradual approach to a steady state, the process of provision implied the existence of at least one intermediate. The intermediate was taken as a non-insulin activator of insulin provision but could also be an intermediate form of insulin itself.

For convenience, we have assumed that filling by provision occurs with the same distribution function as that found initially. Additionally, a redistribution process within the labile compartment, allows distribution to return toward the initial state with time.

Kinetics of the provisionary factor $P(G, t)$ is assumed to be of the first order:

$$
\dot{P}(G, t)=\alpha(G)(P(G, \infty)-P(G, t)),
$$

with $\alpha(\mathrm{G})$ being the nonspecific disappearance rate coefficient, possibly a function of glucose concentration and, $P(G, \infty)$, the steady state of $P(G, t)-a$ definite function of glucose concentration. The product, $\alpha(\mathrm{G}) \mathrm{P}(\mathrm{G}, \infty)$, is, for any glucose concentration, the steady-state production rate of the provisionary or potentiation factor.

Analogously to equation 4 we describe the rate of change of the amount of insulin in the packets of threshold $\theta$, for $\theta<\mathrm{G}$ as :

$$
\begin{array}{r}
\xi(\theta, \mathrm{t})=-\mathrm{m} \xi(\theta, \mathrm{t})+\gamma(\theta) \mathrm{P}(\mathrm{G}, \mathrm{t})-\Gamma^{\prime}(\infty) \xi(\theta, \mathrm{t}) \\
+\gamma^{\prime}(\theta) \int_{0}^{\infty} \xi\left(\theta^{\prime}, \mathrm{t}\right) \mathrm{d} \theta^{\prime}
\end{array}
$$

and for $\theta>\mathrm{G}$, as :

$$
\begin{aligned}
\xi(\theta, \mathrm{t})=\gamma(\theta) \mathrm{P}(\mathrm{G}, \mathrm{t})-\Gamma^{\prime}(\infty) \xi(\theta, \mathrm{t}) & \\
& +\gamma^{\prime}(\theta) \int_{0}^{\infty} \xi\left(\theta^{\prime}, \mathrm{t}\right) \mathrm{d} \theta^{\prime} .
\end{aligned}
$$

The first term in equation 10 describes release from the packets. The second term in equation 10 indicates the refilling process via the provisionary factor $P(G, t)$ whose effectiveness $\gamma(\theta)$ is proportional to the initial density distribution function, $\gamma(\theta)=f \xi(\theta, 0)$. The third and fourth terms represent the redistribution process with a weighting function again derived from the initial

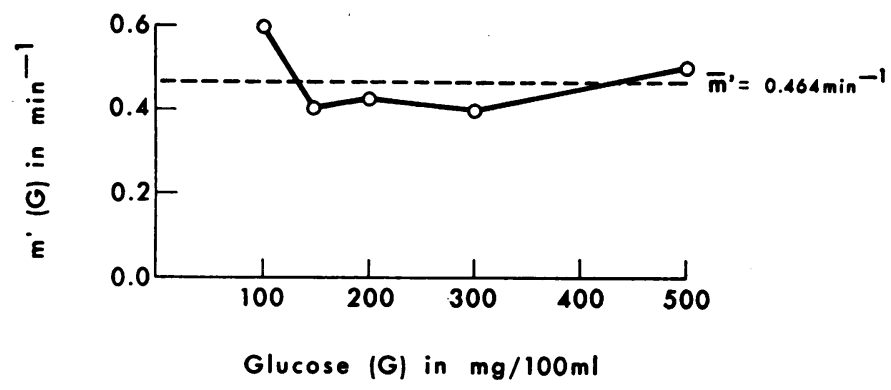

Figure 8 Apparent rate coefficient of insulin release from the small compartment, $\mathrm{m}^{\prime}$, as a function of glucose concentration. This coefficient was calculated as the ratio, height/area, of the early release phases shown in Fig. 2. Broken line indicates the mean value, $\overline{\mathrm{m}}^{\prime}$, used for all computer simulations. 


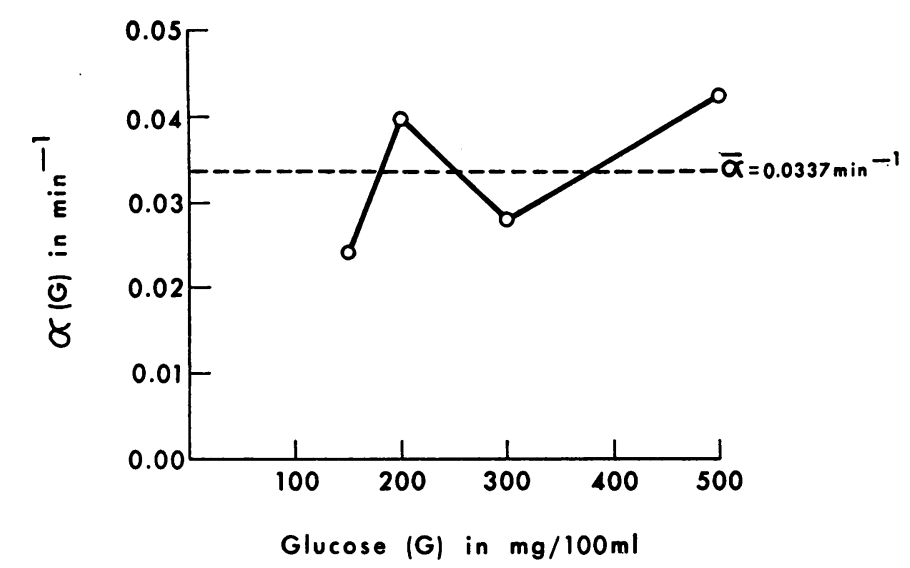

FIGURE 9 Rate coefficient, $\alpha$, for disappearance of $P$ as a function of glucose concentration. Broken line represents the mean, $\bar{\alpha}$, which was used in all computer simulations.

density distribution function, $\gamma^{\prime}(\theta)=f^{\prime} \xi(\theta, 0) . \Gamma^{\prime}(\infty)$ $=\int_{0}^{\infty} \gamma^{\prime}(\theta) \mathrm{d} \theta$ is the redistribution coefficient.

By integrating equation 10 between 0 and $G$ and equation 11 between $G$ and $\infty$, we arrive at the rate of change of the total releasable amount of insulin by constant glucose concentration G :

$$
\begin{aligned}
\dot{X}_{1}(G, t)=\int_{0}^{G} \xi(\theta, t) d \theta= \\
=-m X_{1}(G, t)+\Gamma(G) P(G, t) \\
\quad-\Gamma^{\prime}(\infty) X_{1}(G, t) \\
\quad+\Gamma^{\prime}(G)\left\{X_{1}(G, t)+X_{2}(G, t)\right\},
\end{aligned}
$$

and the rate of change of the amount of nonreleasable insulin by glucose concentration $\mathrm{G}$ :

$$
\begin{aligned}
\dot{\mathrm{X}}_{2}(\mathrm{G}, \mathrm{t})= & \int_{\mathrm{G}}^{\infty} \xi(\theta, \mathrm{t}) \mathrm{d} \theta= \\
= & \{\Gamma(\infty)-\Gamma(\mathrm{G})\} \mathrm{P}(\mathrm{G}, \mathrm{t}) \\
& +\left\{\Gamma^{\prime}(\infty)-\Gamma^{\prime}(\mathrm{G})\right\} \mathrm{X}_{1}(\mathrm{G}, \mathrm{t}) \\
& \quad-\Gamma^{\prime}(\mathrm{G}) \mathrm{X}_{2}(\mathrm{G}, \mathrm{t}) .
\end{aligned}
$$

In this equation:

$$
\Gamma(\mathrm{G})=\int_{0}^{\mathrm{G}} \gamma(\theta) \mathrm{d} \theta, \quad \Gamma^{\prime}(\mathrm{G})=\int_{0}^{\mathrm{G}} \gamma^{\prime}(\theta) \mathrm{d} \theta
$$

and the refilling coefficient is:

$$
\Gamma(\infty)=\int_{0}^{\infty} \gamma(\theta) \mathrm{d} \theta
$$

At the steady state, the secretion rate (both instantaneous and one minute integral) becomes:

$$
\begin{aligned}
\mathrm{S}_{0}(\mathrm{G}, \infty)=\mathrm{S}(\mathrm{G}, \infty)=\mathrm{mX}_{1}(\mathrm{G}, \infty) & \\
& =\Gamma(\infty) \mathrm{P}(\mathrm{G}, \infty)
\end{aligned}
$$

Though exact details of the refilling processes require additional testing, some clues are available as to their nature under special circumstances. For large values of G (above $300 \mathrm{mg} / 100 \mathrm{ml}$ ), the labile system is practically exhausted and therefore the redistribution process within it is insignificant. Thus, the right hand side of equation 13 tends to zero: the first two terms dwindle on account of the vanishing differences enclosed in brackets and the third term becomes small because $X_{2}(G, t)$ is the integral between $G$ and $\infty$ of a function vanishing for $G$ above $300 \mathrm{mg} / 100 \mathrm{ml}$. Thus, equation 12 becomes approximately:

$$
\dot{\mathrm{X}}_{1}(\mathrm{G}, \mathrm{t}) \doteq-\mathrm{mX}_{1}(\mathrm{G}, \mathrm{t})+\Gamma(\infty) \mathrm{P}(\mathrm{G}, \mathrm{t}),
$$

suggesting a linear differential equation with two unknown parameters, $\alpha(G)$ and $\Gamma(\infty) \mathrm{P}(\mathrm{G}, \infty)$ (cf. equations 9 and 14). By the method of least squares, we found a satisfactory fit to the linear processes described by equations 9 and 15, even for other values of glucose concentration. The results of the least squares analysis are shown in Fig. 9. They suggest that $\alpha(G)$ does not vary with $G$.

Function $\Gamma(\infty) \mathrm{P}(\mathrm{G}, \infty)$, which determines the ultimate steady-state maximum secretion rate of the provisionary phase, was approximated for the purpose of simulations by:

$$
\begin{aligned}
& \Gamma(\infty) \mathrm{P}(\mathrm{G}, \infty) \\
& =\frac{0.5 \mathrm{G}^{10}}{8.875 \times 10^{21}+2.25 \times 10^{15} \mathrm{G}^{3}+3.5 \times 10^{6} \mathrm{G}^{7}+\mathrm{G}^{10}} .
\end{aligned}
$$

The values of this function at different glucose concentrations are shown in Fig. 10. Note that although the value of this function at $\mathrm{G}=100 \mathrm{mg} / 100 \mathrm{ml}$ is 


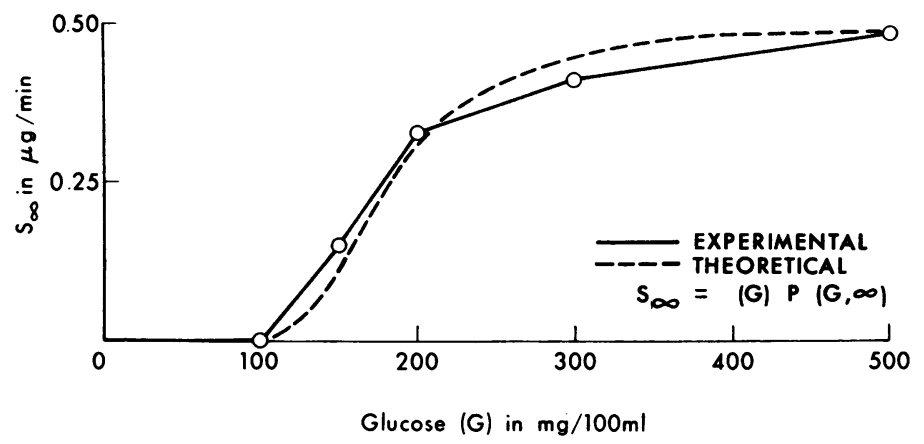

FIGURE 10 Maximum secretion rate of insulin release during the second or provisionary phase as a function of glucose concentration. Data in open circles were obtained by least squares fit from the data in Fig. 2. Broken line is the theoretical curve and represents the product of the integral distribution function and the asymptotic value of $\mathrm{P}$ for different glucose concentrations.

finite, it appears to be zero because of the graphical problem to plot $0.0043 \mu \mathrm{g} / \mathrm{min}^{4}$ on that scale.

Equations 12 and 13 were used for the simulations; as noted on page 2052, the comparatively small contribution to release by exchange from the large compartment was not included in these formulations but was in the actual simulations.

Ramp function stimulations. In these types of stimulations, the availability of insulin increases continuously with time at a rate $R(t)$ so that the total amount of insulin at any time,

$$
\mathrm{X}\{\mathrm{G}(\mathrm{t}), \mathrm{t}\}=\int_{0}^{\mathrm{G}(\mathrm{t})} \xi(\theta, \mathrm{t}) \mathrm{d} \theta
$$

will change as follows:

$$
\begin{aligned}
\dot{X}\{G(t), t\}=R(t)-m X\{G(t), t\} & \\
& +\Gamma(\infty) P\{G(t), t\},
\end{aligned}
$$

where approximation 15 was used for simplicity. The function $R(t)$ is determined by considering the contribution of insulin from the various packets when glucose increases by $\mathrm{dG}$. Then, the insulin contribution is $\xi\{G(t), t\} d G$ and the rate is this insulin contribution divided by the time interval $\mathrm{dt}$ over which it occurs. viz. :

$$
R(t)=\xi\{G(t), t\} \frac{d G(t)}{d t} .
$$

For the ramp function the rate of change of glucose concentration is constant, hence,

$$
\frac{d G(t)}{d t}=c .
$$

\footnotetext{
${ }^{4}$ This rate is approximately one-half that which would be detectable by the assay procedures used (Fig. 2) but could make a significant contribution to the low threshold packets during a post stimulation rest period.
}

The simulations were performed by employing the differential equation :

$$
\begin{aligned}
\dot{X}\{G(t), t\}=\xi\{G(t), t\} c- & m X\{G(t), t\} \\
& +\Gamma(\infty) P\{G(t), t\} .
\end{aligned}
$$

The one-minute secretion rates

$$
\mathrm{S}\{\mathrm{G}(\mathrm{t}), \mathrm{t}\}=\mathrm{m} \int_{\mathrm{t}}^{\mathrm{t}+1} \mathrm{X}\{\mathrm{G}(\tau), \tau\} \mathrm{d} \tau
$$

were plotted in Figs. 4 and 5 .

\section{Application of theoretical model}

Fig. 1 shows that the mathematical model approximates results obtained when glucose was presented to the pancreas in a series of steps of increasing concentration (staircase). Each response reflects mobilization of those packets in the small labile storage form whose thresholds are encompassed by a given glucose level minus those released by a previous step. Because of the bell-shaped distribution of these packets (Fig. 7), only a small amount of insulin was released during stimulation with low glucose $(100 \mathrm{mg} / 100 \mathrm{ml})$. Most of the remaining components are sensitive up to mid-range concentrations of glucose; therefore, when glucose levels were increased to $150 \mathrm{mg} / 100 \mathrm{ml}$ a large response occurred. A smaller number of high threshold packets are present to respond to the $200 \mathrm{mg} / 100 \mathrm{ml}$ glucose step. During the $20 \mathrm{~min}$ of this experiment, provision slowly increased with increasing glucose concentration, contributing to the progressive rise in secondary insulin secretion.

Fig. 2 shows comparison of the theoretical curves with the experimental results when various concentrations of glucose up to $500 \mathrm{mg} / 100 \mathrm{ml}$ were presented to the pancreas as single prolonged step stimulations. Examination of the variables and constants used to fit 
the experimental results from Fig. 2 reveals that the provisionary factor, $\mathrm{P}$, becomes large by the end of the perfusion period. The disappearance constant $\alpha$ is small so that $\mathrm{P}$ is dissipated slowly. When glucose stimulation is stopped, both release of insulin and production of $\mathbf{P}$ halt immediately. The model, however, predicts that the pancreas has not reverted to its original state since the residual $P$ continues to provide insulin into the labile storage form. Since this insulin exchanges only slowly with the large compartment, its concentration continues to increase and can exceed that present even at the beginning of the experiment. Thus, after a $5 \mathrm{~min}$ rest, insulin secretion rates were greater after restimulation than those achieved at any time during the first hour (Fig. 3).

Figs. 4 and 5 give the theoretical and experimental results when glucose was presented to the pancreas in constantly increasing concentrations (ramp functions). According to the model, when glucose concentrations were increased to high levels during a $5 \mathrm{~min}$ period instead of as a rapid step (Fig. 4), the rate of increase in glucose concentration was still sufficiently fast to mobilize most of the available insulin in the labile storage system within minutes after the minimal threshold was achieved.

When a period of $1 \mathrm{hr}$ was used to increase glucose from 50 to $250 \mathrm{mg} / 100 \mathrm{ml}$ (Fig. 5), depletion theoretically was slow; experimentally, insulin secretion gradually increased with little evidence of diphasic responses.

\section{DISCUSSION}

The threshold distribution hypothesis for packet storage of insulin. If increased glucose (or one of its metabolic signals) acts by simple mass action to increase the number of collisions on a homogeneous set of targets, a continuous sub-maximal glucose stimulation would be expected to cause a moderate release of insulin, declining only as total insulin in the labile form became slowly exhausted; total insulin released at all glucose concentrations would eventually be identical.

However, our staircase experiments showed that the initial spike of insulin release (at $100 \mathrm{mg}$ glucose/100 $\mathrm{ml}$ ) was not simply depletion of a labile compartment; increase of glucose to $150 \mathrm{mg} / 100 \mathrm{ml}$ caused an additional spike in which even larger amounts of insulin were released. Similarly, in the single step experiments, the amount of insulin released during the initial spike was greater with higher glucose concentrations. In all cases, the observed patterns of the early release phase were the same whether marginal, submaximal, or maximal glucose levels were used; secretion rates rose and fell within 3-4 min and the ratio of maximum secretion rate (height of spike) to total insulin released (area under the spike) was constant. The sum of total insulin released as spikes in the staircase series leading to a given glucose concentration was the same as when that concentration was used as a single step. These experiments are consistent with a sensitivity or threshold distribution hypothesis in which insulin is not stored in homogeneous form but as a distribution of packets (see model, Fig. $6 \mathrm{a}$ and $\mathrm{b}$ ); these packets respond similarly and quickly when their threshold levels to glucose are reached or exceeded.

Insulin released during the initial phase was a sigmoidal function of glucose concentration (Fig. 7). The half-maximum for glucose of approximately $135 \mathrm{mg} / 100$ $\mathrm{ml}$ and a maximum of $300-500 \mathrm{mg} / 100 \mathrm{ml}$ were similar to those found in man (14), or after static incubation of rat islet preparations (15). There can be many interpretations of a sigmoidal response (e.g., an associative enzymatic process); however, sigmoidal patterns when differentiated mathematically yield a bell-shaped distribution function. In our case, the somewhat skewed bell-shaped curve could be taken as the distribution of insulin packets as to their glucose thresholds. It is seen that only a small number of packets are capable of responding at low concentrations of glucose $(100 \mathrm{mg} /$ $100 \mathrm{ml}$ ), more respond by mid-range concentrations $(150 \mathrm{mg} / 100 \mathrm{ml})$, and a small additional number are found with a threshold to glucose of $200 \mathrm{mg} / 100 \mathrm{ml}$.

Significance of increment vs. concentration of stimulator as the modulator for insulin secretion. The staircase studies show that insulin release may not be determined by the absolute increment of a stimulus. In these experiments the amounts of secreted insulin differed for each step though the glucose increments were the same $(50 \mathrm{mg} / 100 \mathrm{ml})$. Secretion may be determined, instead, by the number of packets whose threshold to glucose is reached during a particular step, minus those previously released. Therefore, if the initial stimulation is sufficiently low to affect only the relatively few low threshold packets (e.g., $100 \mathrm{mg} / 100 \mathrm{ml}$ ), a subsequent increase in concentration $(150 \mathrm{mg} / 100 \mathrm{ml})$ would cause a sharply increased insulin release. This could explain the increased response of the pancreas to a sudden higher glucose stimulation noted by others $(16,17)$ who understandably could not explain the results on the basis of a single labile compartment. However, if the initial stimulation is comparatively high $(150 \mathrm{mg} / 100 \mathrm{ml})$ a stepwise increase may activate only a few more packets and the pancreas would appear refractory to the higher stimulation. We previously reported this phenomenon (1) before development of the threshold distribution hypothesis.

It is often assumed that if a staircase stimulation of constant increment produces the same quantitative response, secretion depends on the change of concentration rather than the actual concentration of the stimulator. This may be invalid, however, since from 
the present model, it is possible to establish glucose concentrations which theoretically would elicit the same amount of insulin after constant increments (for example: constant increments in the comparatively linear portion of the sigmoidal curve (Fig. 7) from $120-180 \mathrm{mg} / 100 \mathrm{ml}$ ).

Effect of rate of stimulation on insulin release. When glucose was presented to the pancreas as ramp functions of gradually increasing concentration instead of as instantaneous steps, the predictions of the packet model closely approximated experimental results. Steep ramp functions encompassing 5-10 minutes still represented a rapid stimulation with quick emptying of the labile storage form and a blunted but predicted multiphasic response. With ramp functions of $60 \mathrm{~min}$ the secretion increased at a smoothly accelerating rate with marginal evidence of an early release phase. Under these conditions depletion of the sensitive packets was too slow to produce the typical dumping seen during step stimulations.

Other mathematical models for insulin release often incorporate empirically both an amount and a rate function for glucose action (18). As noted in equations 16 and 17 , both rate and concentration sensitive processes are an integral part of the packet model without requiring further empirical assumptions. Furthermore, equation 14 shows that the rate sensitive process is weighted by the distribution function itself. Thus it is most effective at the peak of the distribution curve and less effective at very low or very high glucose concentrations.

The minimal detectable threshold to glucose was not rate sensitive but was the same $(70-90 \mathrm{mg} / 100 \mathrm{ml}$ ), whether glucose was presented rapidly as single step or staircase functions or presented as ramp functions of different rates. This is consistent with the model whereby the threshold for detectable release should be determined by the sensitivity of the packets to glucose at the low end of the bell-shaped distribution and independent of glucose rate of change.

Though results of ramp type experiments are rarely severe tests of any mathematical model, they illustrate that the slow rise of glucose which occurs postprandially or after an oral glucose tolerance test in man should not produce detectable phases of insulin secretion.

Refilling or reactivation of the labile packets. In the model (Fig. 6), reactivation of the threshold-sensitive packets arises from three sources: $(a)$ basal reversible exchange between the labile and comparatively stable compartments; $(b)$ redistribution of packets within the labile system to reapproach the original distribution of threshold sensitivities; $(c)$ direct potentiating action of glucose to increase provision of additional insulin to the labile packet system. Each factor may contribute to reactivation simultaneously but can differ in quantita- tive significance depending on the circumstances. After short pulse stimulations at comparatively low glucose or after stimulation with agents such as the sulfonylureas which have little effect on provision $(1,2)$, the first two phenomena (though small with respect to time) play a proportionally great role in the replenishment of labile insulin. However, after prolonged, comparatively high glucose, glucose-stimulated provision or potentiation becomes the most important contributing factor.

For provision, a hypothetical agent, $\mathrm{P}$ is used to mathematically cause the delayed second phase of insulin release. It was assumed that $P$ provides insulin in the same distribution as that initially found in the labile form. However, this is not an essential feature of the threshold distribution hypothesis and will be subject to further testing. The source of the insulin supplied by $\mathrm{P}$ is also not established. If newly produced insulin arising either from de novo synthesis or conversion from proinsulin or other precursors is the source, it could be preferentially released from the pancreas (see model option Fig. 6a). This concept of preferential release of newly formed insulin was initially proposed from analysis of our preliminary model (9) and has been suggested for other endocrine systems $(19,20)$. However, experimental support based on the incorporation of labeled amino acids into insulin and the preferential secretion of proinsulin is inconsistent (21-26). Alternatively, the model is equally applicable if the provisionary action of glucose is assumed to act on the conversion of the stable insulin stored in the large compartment to the more labile form. An important feature of this option is that it provides for the possibility that some insulin can be released directly from the large stable form without being regulated by the factors controlling release from the smaller one. With this option, de novo synthesis would play only a minor role by adding slowly to the stable stored insulin.

When high glucose is stopped after a prolonged stimulation, the residual $\mathrm{P}$ temporarily continues to provide additional insulin into the resting labile system which can become superfilled. This can account for the hypersensitivity of the pancreas noted when prolonged glucose or calcium is followed by a rest and restimulation in vitro (Fig. 3 and reference 27). A similar hypersensitivity to prolonged glucose has been produced in man (4).

Both phases of insulin release had similar sensitivities to glucose, indicated by the identical half-maximum and maximum effective glucose concentrations obtained for each phase (Fig. 7 and 10). Thus, a common glucoreceptor or glucose-mediated signal may exist. Since both insulin phases are depressed in the mild diabetic (28), the defect in this condition may be at the level of the initial glucose sensitivity. 
The provisionary mechanism on which glucose acts is metabolically different from the mechanism for release. In contrast to initial release, the provisionary phase is partially blocked by puromycin (2) or cyclohexamide (29). As we previously noted $(2,8)$, this probably indicates a partial dependence of the second phase on some rapidly turning over protein; numerous studies suggest this phase occurs too promptly $(21,22,30)$ to be explained solely on the basis of a glucose stimulation of insulin synthesis. The secondary phase is more dependent on maintenance of the electron transport system than initial release since it can be strongly inhibited by oligomycin (personal observations) and enhanced by energy sources (31). Electron microscopic examination of the pancreas reveals that there is increased Golgi activity during the provisionary phase and the appearance of newly formed granules in this organelle (32). Thus, a specific inhibition of either phase could occur with drug action or in clinical states, though basic sensitivity to glucose may remain intact.

General considerations. A series of observations now support the proposal based on model analysis $(7,8)$ that insulin may exist in more than one storage form. The large stable form in the model may reflect the typical storage granules. The labile storage form may include : $\beta$-cell granules aligned along microtubules (33); pale granules which are increased in conditions associated with increased insulin secretion $(34,35)$; or the small microvesicles located in or around the Golgi apparatus (36-39). Also, the labile storage form may simply represent a geographical localization of granules at a site readily available to stimulating agents. Within any of these storage systems, a normal distribution of packets differing in maturation, localization, and sensitivity to glucose is not unlikely. Concurrent to our development of the threshold distribution hypothesis for insulin storage, Matthews and Dean (40) observed that an increased number of $\beta$-cells initiate action potential discharges with increasing glucose concentrations. Though it is unknown if these studies directly relate to the rapid phase of insulin release, they suggest the threshold sensitive characteristic could be among $\beta$-cells rather than within a single cell.

It is emphasized that no mathematical model can describe all the complexities of a physiologic process. Additional testing is required to establish characteristics of direct release from the large stable storage form, as well as the exact quantitative contribution to reactivation of the labile system by exchange, redistribution, and by provision. The possible role of feed-back inhibition by stimulator $(1,41)$ or insulin $(42-47)$ also needs clarification. Stimulator-induced inhibition could take a form in which the spike responses are caused by temporary differences in signal levels which quickly equilibrate during continued stimulation.
Though the model suggests compartmentation and threshold distributions are at the level of stored insulin, the data could be explained by a similar distribution of a metabolic signal whose transient changes directly control insulin release. Our current studies suggest calcium causes similar insulin secretion patterns as glucose (19) indicating it acts in conjunction or in sequence with glucose but is not the threshold-sensitive target.

Despite its incompleteness, the model, incorporating the hypothesis of threshold distribution of packets of insulin, has permitted simulation of insulin responses to a variety of glucose stimulation patterns. It is emphasized that all data used to generate the quantitative relationships came from the single step experiments exclusively and were used unchanged for the other simulations. Also, experimental results, described years before development of the model (1), showed good fit when compared to simulations.

Other secretion systems of ten respond to constant stimulation with multiphasic secretion patterns. These include release of acetylcholine (13), parathyroid hormone (12), vasopressin (20), adrenocorticoids (48), and glucagon (49). Furthermore the existence of unit packets has been proposed to play a role in release of acetylcholine (50). It seems possible therefore that the threshold distribution hypothesis for packet storage, developed from kinetic studies of insulin release, may have general applicability to many neurologic, exocrine, and endocrine systems.

\section{ACKNOWLEDGMENTS}

I am particularly grateful to Dr. V. Licko for his many contributions to this project, particularly in the development of the mathematical formulations and the computer applications, and to Doctors L. Bennett and D. Curry who were involved with some of the earlier experiments. I also wish to acknowledge the technical assistance of Mr. R. Fanska, D. Smith, and Misses F. Schmid and B. Lewis; and the advice and suggestions of Dr. H. D. Landahl.

This work was supported in part by a Special Grant from the Regents of the University of California; H. E. W. General Research Support Grant RR 05355; Grant AM 01410 from the National Institutes of Arthritis and Metabolic Diseases, U. S. Public Health Service; a grant from the Hoechst Pharmaceutical Company, Somerville, N. J.; and by a grant from the Levi J. and Mary Skaggs Foundation.

\section{REFERENCES}

1. Grodsky, G. M., L. L. Bennett, D. Smith, and K. Nemechek. 1967. The effect of tolbutamide and glucose on the timed release of insulin from the isolated perfused pancreas. In Tolbutamide after Ten Years. W. J. H. Butterfield and W. Westering, editors. Excerpta Medica Foundation, Amsterdam. 11.

2. Curry, D. L., L. L. Bennett, and G. M. Grodsky. 1968. Dynamics of insulin secretion by the perfused rat pancreas. Endocrinology. 83 : 572. 
3. Bennett, L. L., and G. M. Grodsky. 1969. Multiphasic aspects of insulin release after glucose and glucagon. In Diabetes. J. Ostman and R. D. G. Miller, editors. Excerpta Medica Foundation, Amsterdam. 461.

4. Porte, S. and A. A. Pupo. 1969. Insulin responses to glucose: Evidence for a two pool system in man. J. Clin. Invest. 48, 2309.

5. Cerasi, E., and R. Luft. 1967. The plasma insulin response to glucose infusion in healthy subjects and in diabetes mellitus. Acta Endocrinol. 55: 278.

6. Andres, R., T. Pozefsky, R. S. Swerdloff, and J. D. Tobin. 1970. Effect of aging on carbohydrate metabolism. In Early Diabetes R. Camerini-Davalos and H. S. Cole, editors. Academic Press, Inc., New York. 349.

7. Grodsky, G. M., H. Landahl, D. L. Curry, and L. L. Bennett. 1970. A two-compartmental model for insulin secretion. In Early Diabetes. R. Camerini-Davalos and H. S. Cole, editors. Academic Press, Inc., New York. 45.

8. Grodsky, G. M., D. Curry, H. Landahl, and L. Bennett. 1969. Further studies on the dynamic aspects of insulin release in vitro with evidence for a two-compartmental storage system. Acta Diabetol. Lat. 6 (Suppl. 1) : 554.

9. Grodsky, G. M., H. Landahl, D. L. Curry, and L. L. Bennett. 1970. In vitro studies suggesting a two-compartmental model for insulin secretion. In The Structure and Metabolism of the Pancreatic Islets. S. Falkmer, B. Hellman, and I. B. Taljedal, editors. Pergamon Press Ltd., Oxford. 409.

10. Grodsky, G. M., J. Lee, V. Licko, and H. Landahl. 1971. Characteristics of multiphasic insulin release in vitro. In Diabetes. Proceedings of the 7th Congress of the International Diabetes Federation, Buenos Aires, 1970. 427.

11. Grodsky, G. M. 1970. Insulin and the Pancreas. Vitam. Horm. $28: 37$.

12. Sherwood, L. M., G. P. Mayer, C. F. Ramberg, Jr., D. S. Kronfeld, G. D. Aurbach, and J. T. Potts, Jr. 1968. Regulation of parathyroid hormone secretion: proportional control by calcium, lack of effect of phosphate. Endocrinology. 83 : 1043.

13. Brown, G. L., and W. Feldberg. 1936. The acetylcholine metabolism of a sympathetic ganglion. J. Physiol. 88: 265.

14. Karam, J. H., K. N. Ching, K. Burrill, F. G. Schmid, and G. M. Grodsky. 1971. Stepwise stimulation of insulin secretion: evidence for multicompartmentalization and multiphasic insulin release in man. Diabetes. 20 (Suppl. 1) : 323.

15. Malaisse, W. J., F. Malaisse-Lagae, and P. H. Wright. 1967. A new method for the measurement in vitro of pancreatic insulin secretion. Endocrinology. 80: 99.

16. Iverson, J., and D. W. Miles. 1971. Evidence for a feedback inhibition of insulin on insulin secretion in the isolated, perfused canine pancreas. Diabetes. 20: 1 .

17. Cerasi, E., I. Chowers, R. Luft, and A. Widstrom. 1969. The significance of the blood glucose level for plasma insulin response to intravenously administered tolbutamide in healthy subjects. Diabetologia. $5: 343$.

18. Foster, R. O. 1970. The dynamics of blood sugar regulation. Master of Science Thesis, Massachusetts Institute of Technology, July.

19. Sachs, H., and E. W. Haller, 1968. Further studies on the capacity of the neurohypophysis to release vasopressin. Endocrinology. 83 : 251.

20. Haibach, H., and I. Kobayashi. 1970. Studies on the preferential secretion of new iodine by the rat thyroid. Clin. Res. 18: 121.
21. Sorensen, R. L., M. W. Steffes, and A. W. Lindall, 1970. Subcellular localization of proinsuling to insulin conversion in isolated rat islets. Endocrinology. 86: 88 .

22. Tanese, T., N. R. Lazarus, S. Devrim, and L. Recant. 1970. Synthesis and release of proinsulin and insulin by isolated rat islets of langerhans. J. Clin. Invest. 49: 1394.

23. Clark, J. L., and D. F. Steiner 1969. Insulin biosynthesis in the rat: demonstration of two proinsulins. Proc. Nat. Acad. Sci. U.S.A. 62: 278.

24. Malaisse, W., and F. Malaisse-Lagae. 1970. A possible role for calcium in the stimulus-secretion coupling for glucose induced insulin secretion. Acta Diabetol. Lat. 7 (Suppl. 1) : 264 .

25. Burr, I. M., L. Balant, W. Stauffacher, A. E. Renold, and G. Grodsky. 1969. Dynamic aspects of proinsulin release from perifused rat pancreas. Lancet. 2: 882 .

26. Melani, F., A. H. Rubenstein, and D. F. Steiner. 1970. Human serum proinsulin. J. Clin. Invest. 49: 497.

27. Grodsky, G. M. 1972. A threshold distribution hypothesis for packet storage of insulin. II. Effect of calcium. Diabetes. In press.

28. Cerasi, E., R. Luft, and S. Efendic. 1972. Decreased sensitivity of the pancreatic beta cells to glucose in prediabetic and diabetic subjects: a glucose dose-response study. Diabetes. $21: 224$

29. Basabe, J., N. Lopez, J. Viktora, and F. Wolff. 1970. Studies of insulin secretion in the perfused rat pancreas. Effect of diazode and A025. Diabetes. 19: 271.

30. Steiner, D. F. 1969. Proinsulin and the biosynthesis of insulin. Diabetes. 280: 1106.

31. Burr, I. M., L. Balant, W. Stauffacher, and A. Renold. 1970. Perifusion of rat pancreatic tissue in vitro: substrate modification of theophylline-induced biphasic insulin release. J. Clin. Invest. 49: 2097.

32. Lee, J. C., G. M. Grodsky, L. L. Bennett, D. F. SmithKyle, and L. Craw. 1970. Ultrastructure of $\beta$-cells during the dynamic response to glucose and tolbutamide in vitro. Diabetologica. 6: 542.

33. Lacy, P. E., S. L. Howell, D. A. Young, and C. V. Fink. 1968. New hypothesis of insulin secretion. Nature (Lond.) $219: 1177$.

34. Lazarus, S. S., and B. W. Volk. 1970. Ultrastructural aspects of the function of rabbit $\beta$-cells. In The Structure and Metabolism of the Pancreatic Islets. S. Falkmer, B. Hellman, and I. -B. Taljedal, editors. Pergamon Press, New York. 159.

35. Bencosme, S. A., V. Tsutsumi, J. M. Martin, and H. K. Akerblom. 1971. Ultrastructural changes in $\beta$-cells of pancreatic islets from rats with elevated levels of circulating growth hormone secreted by MtT-W15 tumor. Diabetes. 20: 15.

36. Jamieson, J. D., and G. E. Palade. 1965. Role of the Golgi complex in the intracellular transport of secretory proteins. Proc. Nat. Acad. Sci. U.S.A. 55: 424.

37. Orci, L., W. Stauffacher, D. Beaven, A. E. Lambert, A. E. Renold, and C. Rouiller. 1969. Ultrastructural events associated with the action of tolbutamide and glybenclamide on pancreatic $\beta$-cells in vivo and in vitro. Acta Diabetol. Lat. 6: (Suppl. 1) : 271.

38. Like, A. A., and W. L. Chick. 1970. Studies in the diabetic mutant mouse. I. Light microscopy and radioautography of pancreatic islets. Diabetologia. 6:207.

39. Hoyos-Guevara, E. 1969. The pancreatic islet system of the mouse (mus. muscularus): ultrastructural report of six new cell types. Z. Zellforsch. Mikrosk. Anat. 101: 28 .

40. Matthews, E. K., and P. M. Dean. 1970. Electrical activity in islet cells. In The Structure and Metabolism of 
the Pancreatic Islets. S. Falkmer, B. Hellman, and I.-B. Taljedal, editors. Pergamon Press, N. Y. 305.

41. Bennett, L. L., and G. M. Grodsky. 1969. Multiphasic aspects of insulin release after glucose and glucagon. In Diabetes. J. Ostman and R. D. G. Miller, editors. Excerpta Medica Foundation, Amsterdam. 461.

42. Sodoyez, J.-C., Sodoyez-Goffaux, F. and P. P. Foa. 1970. Feed-back regulation of insulin secretion by insulin: role of 3', 5'-cyclic AMP. In The Structure and Metabolism of the Pancreatic Islets. S. Falkmer, B. Hellman, and I. B. Taljedal, editors. Pergamon Press Ltd., Oxford. 445.

43. Malaisse, W., F. Malaisse-Lagae, P. E. Lacy, and P. Wright. 1967. Insulin secretion by isolated islets in presence of glucose, insulin, and anti-insulin serum. Proc. Soc. Exp. Biol. Med. 124 : 497.

44. Frerichs, H., U. Reich, and W. Creutzfeldt. 1965. Insulinsekretion in vitro. I. Hemmung der glucoseinduzierten Insulinabgabe durch Insulin. Klin. Wochenschr. 43: 140.
45. Loubatieres, A. 1968. Stimulators and inhibitors of insulin secretion: physiological and pharmacological interferences, synergisms and antagonisms. Acta Diabetol. Lat. 5 (Suppl. 1):220.

46. Iversen, J., and D. W. Miles. 1971, Evidence for a feedback inhibition of insulin or insulin secretion in the isolated, perfused canine pancreas. Diabetes. 20: 1 .

47. Grodsky, G. M., D. L. Curry, L. L. Bennett, and V. V. Rodrigo. 1968. Factors influencing different rates of insulin release in vitro. In Mechanism and Regulation of Insulin Secretion. R. Levine and E. F. Pfeiffer, editors. Casa Editrice, Milano, Italy. 140.

48. Urquhart, J., and Li, C. C. 1968. The dynamics of adrenocortical secretion. Am. J. Physiol. $214: 73$.

49. Iversen, J. 1971. Secretion of glucagon from the isolated, perfused canine pancreas. J. Clin. Invest. 50: 2123.

50. Katz, B. 1969. The Release of Neural Transmitter Substances. Liverpool University Press, Liverpool. 